\title{
Kinetics of Oxidation of Ethylenediammine-N,N,N',N'-tetraacetatocobaltate(II) complex by Silver-activated Persulphate ion in Aqueous Acidic Medium
}

\author{
${ }^{* 1}$ A.D. Onu, ${ }^{2}$ S.O. Idris and ${ }^{1} Y$. Ahmed \\ ${ }^{1}$ Department of Chemistry Federal College of Education, Zaria \\ 2Department of Chemistry Ahmadu Bello University, Zaria \\ [ ${ }^{*}$ Corresponding Author: daveonu@gmail.com; ?:+2348032894966]
}

\section{ABSTRACT}

The kinetics of oxidation of Ethylenediammine-N,N,N',N'-tetraacetatocobaltate(II) complex $\left([\mathrm{Co}(\mathrm{II}) \mathrm{EDTA}]^{2-}\right)$ by silver-activated persulphate ion in aqueous nitric acid medium was studied at $\mathrm{I}=0.5 \mathrm{~mol} \mathrm{dm}^{-3}\left(\mathrm{NaNO}_{3}\right),\left[\mathrm{H}^{+}\right]=1 \times 10^{-2} \mathrm{~mol} \mathrm{dm}^{-3},\left[\mathrm{Ag}^{+}\right]=1 \times 10^{-2} \mathrm{~mol} \mathrm{dm}^{-3}, \mathrm{~T}=299 \pm 1 \mathrm{~K}$ and $\lambda_{\max }=520$ $\mathrm{nm}$. Stoichiometric study showed 2:1 (Reductant: Oxidant) mole ratio. The reaction exhibited first order with respect to the [Co(II)EDTA2-] and $\left[S_{2} O_{8}^{2-}\right]$ and the rate constant, $\mathrm{k}_{2}\left(5.90 \times 10^{-2} \mathrm{dm}^{3} \mathrm{~mol}^{-1} \mathrm{~s}^{-1}\right)$ was independent of the acid concentration, but varied linearly with catalyst concentration, $\left[\mathrm{Ag}^{+}\right]$. The overall rate law is represented as:

$$
\frac{\mathrm{d}\left[\mathrm{Co}(\mathrm{III}) \mathrm{EDTA}^{-}\right]}{\mathrm{dt}}=5.90 \times 10^{-2}\left[\mathrm{Ag}^{+}\right]\left[\mathrm{Co}(\mathrm{II}) \mathrm{EDTA}^{2-}\right]\left[\mathrm{S}_{2} \mathrm{O}_{8}^{2-}\right]
$$

The reaction displayed zero salt effect suggesting an activated complex composed of either a neutralcharged, neutral-neutral reactant species or ion-pair. The reaction was catalysed by addition of formate ion, HCOO- and the Michaelis-Menten's type plot gave zero intercept indicating the absence of intermediate complex. Also, the activation enthalpy $\left(\Delta \mathrm{H}^{\#}=+39.27 \mathrm{~kJ} \mathrm{~mol}^{-1}\right)$ and entropy $\left(\Delta \mathrm{S}^{\#}=-136.73 \mathrm{~J} \mathrm{~K}^{-1} \mathrm{~mol}^{-1}\right)$ were determined. The entropy of activation shows a more ordered activated complex relative to the reactants species. Evaluating the experimental data, an outer-sphere mechanistic pathway via ion pair activated complex is proposed for the reaction.

Keywords: Kinetics, Oxidation, Aminocarboxylactocobaltate(II), Persulphate ion

\section{INTRODUCTION}

Bioactive molecules containing hard and soft donor sites of $\mathrm{N}, \mathrm{O}$ and $\mathrm{S}$ atoms occur generally in nature (Dharmaraja et al., 2017) in form of metal complexes. For example, vitamin B12, a complex of cobalt which is necessary for DNA synthesis, formation of red blood cells, maintenances of central nervous system, myelin formation, etc. (Chang, 2000). An aminopolycarboxylic acid is a chemical compound containing one or more nitrogen atoms connected through carbon atoms to two or more carboxyl groups. It forms strong complexes with metal ions (Anderegg et.al, 2005). This property makes it useful complexone in a wide variety of chemical, environmental and medical applications. Metal amino carboxylate complexes are important in metalloenzyme catalyzed reactions (Vuckovic et. al., 2011) and as model for mimicking biological processes like respiration (Swaroop et.al., 1991). Thus, the study of oxidation of these complexes has continued to receive wide attention. Electron transfer reactions of these complexes with some oxyanions have been reported (Onu et al., 2008, 2009, 2015 \& 2016; Naik et al., 2007 \& 2010 \& Mansour, 2003). In these studies both the inner-sphere and outer-sphere mechanisms were reported.

Peroxydisulphate ion is one of the strongest oxidants known in aqueous solution (Mcheik and El Jamal, 2013). This plays key role in many industrial processes and commercial products and it is mainly used as a radical initiator for emulsion polymerization reactions for styrene based polymers (Harald, Stefan, Thomas, Sylvia and Sven, 2005). In the electronic industry, it is considered an efficient microetchant in the 
manufacture of printed circuit boards. In the cosmetic, pharmaceutical, organic synthesis, agriculture, plating and coating processes; the use of this oxidant is wide spread. Although redox reactions of peroxydisulphate ion have been studied (Kun-Chang, Richard, and George, 2002, Shen-Xin, DongWei, ZongWei,, XiangRong, Hua-Bin, and Yue, 2009, Mohammed, lyun, and Idris, 2010, Xiang-Rong and XiangZhong, 2010, Xie, , Zhang, Huang, and Huang, 2012 ), studies involving the above titled reaction seems not to have received good attention given the paucity of literature. Understanding the mechanistic pathway for this reaction of interest is therefore desirable. Consequently, the need to gain more understanding of the mechanism of redox reaction of $[\mathrm{Co}(I I) E D T A]^{2-}$ and persulphate ion with a view to improving on their uses; is the driving motive for this study.

\section{MATERIALS AND METHODS}

All chemicals and reagents used were of analar grade and distilled water was used in preparing the solutions. Sodium nitrate was used to maintain the ionic strength of the reaction medium. Nitric acid was used for the investigation of effect of hydrogen ion on the reaction rate and $\mathrm{Ag}^{+}$was used as catalyst.

The $[\mathrm{Co}(\mathrm{II}) E D T A]^{2-}$ was prepared according to the method of Onu et al. (2016) by adding $\mathrm{Na}_{2} \mathrm{H}_{2}$ EDTA to $\mathrm{CoCl}_{2} \cdot 6 \mathrm{H}_{2} \mathrm{O}$ in a ratio such that EDTA was in slight excess to ensure complete complexation. The complex was characterized electronically using uv-visible spectrophotometre. A stock solution of the acid was prepared by diluting nitric acid (70.5\% specific gravity 1.42$)$ and standardized titrimetrically. Stock solution of $\mathrm{NaNO}_{3}$, silver nitrate, sodium persulfate, sodium formate and potassium nitrate were prepared by dissolving accurately weighed amounts of each in a known volume of distilled water.

The stoichiometry of the reaction was determined by spectrophotometric titration using the mole ratio method (Onu et al., 2009 and 2015). The concentration of $[\mathrm{Co}(\mathrm{II}) E D T A]^{2-}$ was kept constant at $5.0 \times 10^{-3} \mathrm{~mol} \mathrm{dm}^{-3}$ while that of
$\mathrm{S}_{2} \mathrm{O}_{8}{ }^{2-}$ was varied 4 folds below and above that of $\mathrm{S}_{2} \mathrm{O}_{8}{ }^{2-}$. The reactions were allowed to go to completion at constant $\left[\mathrm{H}^{+}\right]\left(\mathrm{HNO}_{3}=1.0 \times 10^{-2}\right.$ $\mathrm{mol} \mathrm{dm}-3)$, catalyst $\left(\left[\mathrm{Ag}^{+}\right]=1.0 \times 10^{-2} \mathrm{~mol} \mathrm{dm}^{-3}\right)$, ionic strength $\left(\mathrm{NaNO}_{3}=0.5 \mathrm{~mol} \mathrm{dm}^{-3}\right), \lambda_{\max }=$ $520 \mathrm{~nm} \mathrm{~T}=299 \pm 1 \mathrm{~K}$. This was ascertained by taking the absorbance of the mixtures at intervals. The reaction was taken to be complete when the absorbance remained constant after series of repeated readings and the stoichiometry (indicated by the point of inflexion) of the reaction was determined from the plot of absorbance against mole ratio $\mathrm{S}_{2} \mathrm{O}_{8}{ }^{2}-\left[[\mathrm{Co}(\mathrm{II}) E D T A]^{2}\right.$.

The kinetic study was carried out under pseudofirst order conditions with [Co(II)EDTA $\left.{ }^{2}\right]=5.0 \times$ $10^{-3} \mathrm{~mol} \mathrm{dm}^{-3}$ and $\left[\mathrm{S}_{2} \mathrm{O}_{8}{ }^{2}\right]$ over 12 -folds in excess over the reductant concentration at the condition stated in Table 1 by taking the change in absorbance with time of the reaction mixtures at $520 \mathrm{~nm}\left(\lambda_{\max }\right)$ on a Sherwood Colorimeter 254. The pseudo-first order rate constants $\left(k_{1}\right)$ for the reactions were obtained from the slopes of the plots of $\log \left(A_{\infty}-A_{t}\right)$ versus time; where $A_{\infty}$ is the absorbance at infinity and $A_{t}$ is the absorbance at time $t$. The order with respect to the oxidant concentration $\left(\left[\mathrm{S}_{2} \mathrm{O}_{8}{ }^{2}\right]\right)$ was determined from the slope of the plots of log $\mathrm{k}_{1}$ versus $\log \left[\mathrm{S}_{2} \mathrm{O}_{8}{ }^{2}\right]$. The second order rate constants, $k_{2}$ were obtained from $\mathrm{k}_{1}$ as $\mathrm{k}_{1} /\left[\mathrm{S}_{2} \mathrm{O}_{8}{ }^{2}\right]$.

The effects of change in acid concentration, ionic strength and catalyst on the reaction rate were studied under the reaction condition stated in Table 1 while that of added ions is given by the reaction condition in Table 2. Temperature dependent study from which the thermodynamic parametres were determined was carried out under the reaction condition presented in Table 3.

Presence or otherwise of free radical species in the reaction was checked by addition of $5.0 \mathrm{~cm}^{3}$ of acrylamide to a partially oxidized reaction mixture. This was followed by a large excess of methanol. Formation of polyacrylamide evidenced by gel formation would provide 
information for the presence of free radicals in the reaction mixture.

The $\mathrm{Co}(\mathrm{III})$ reaction product was determined spectrophometrically by scanning the solution of the product within the wavelength range of $350-$ $600 \mathrm{~nm}$. The $\mathrm{SO}_{4}{ }^{2-}$ product was determined qualitatively by adding barium chloride in the presence of excess $\mathrm{HCl}$ acid to the solution of the reaction product(Vogel, 1979). This test was carried out on both the reductant and oxidant respectively.

Activation parameters $\left(\Delta S^{\#}\right.$ and $\left.\Delta \mathrm{H}^{\#}\right)$ were calculated from the intercept and slope of the plot of $\ln (\mathrm{k} / \mathrm{T})$ versus $1 / \mathrm{T}$ using Eyring equation (Atkins and de Paula, 2006) given in (1.0) below.

$\ln \frac{k}{T}=\ln \frac{\kappa}{h}+\frac{\Delta S^{*}}{R}-\frac{\Delta H^{*}}{R T}$

Where, $\mathrm{k}=$ reaction rate constant, $\mathrm{T}=$ Kelvin temperature, $\mathrm{k}=$ Boltzmann's constant, $\mathrm{h}=$ Planck's constant, $\Delta S^{\#}=$ entropy of activation, $\Delta \mathrm{H}^{\#}=$ enthalpy of activation, $\mathrm{R}=$ gas constant.

\section{RESULT}

The electronic spectrum of the complex gave $\lambda_{\max }$ at $520 \mathrm{~nm}$ which was in agreement with literature value (Onu et al., 2009, 2015 \&2016). The result of spectrophotometric titration showed that two moles of the reductant were consumed by one mole of the oxidant. The plots of the titration from which the stoichiometry was determined is presented in Figure 1. Based on this result, the overall stoichiometric equation for the reaction can be represented by:

$2[\mathrm{Co}(I I) E D T A]^{2-+}$

$\mathrm{S}_{2} \mathrm{O}_{8}^{2-} \rightarrow 2[\mathrm{Co}(I I I) E D T A]^{-}+2 \mathrm{SO}_{4}^{2-}(2.0)$

The electronic spectrum of the reaction product showed two $\lambda_{\text {maxima }}$ at $382 \mathrm{~nm}$ and $536 \mathrm{~nm}$ typical of $\mathrm{Co}$ (III) (Mansour, 2003; Perveen et al., 2013 and Onu et.al., 2009, 2015 and 2016) while the qualitative test confirmed the presence of $\mathrm{SO}_{4}{ }^{2-}$ evidenced by the formation of white precipitate insoluble in excess dilute $\mathrm{HCl}$ when $\mathrm{BaCl}_{2}$ was added to the solution of the product of the reaction.

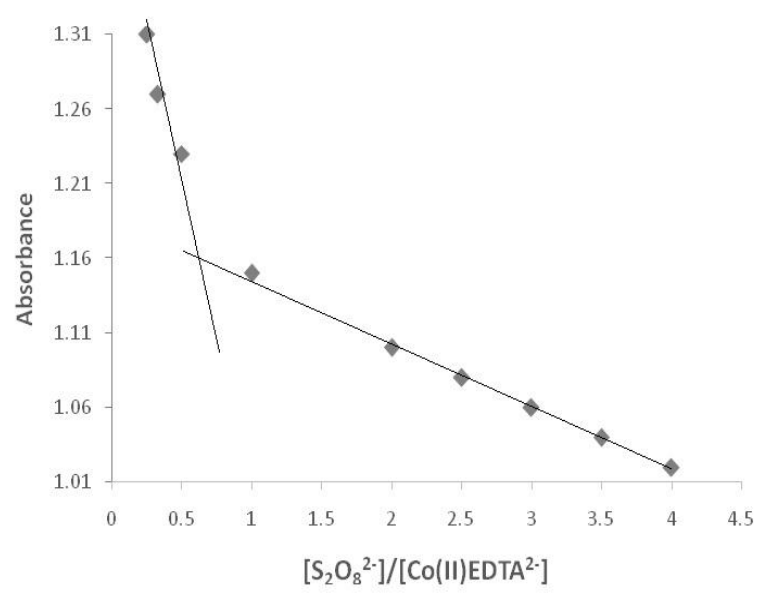

Figure 1: Plot of Absorbance versus mole ratio for the reaction of [Co"EDTA $]^{2-}$ with $\mathrm{S}_{2} \mathrm{O}_{8}{ }^{2-}$

The pseudo - first order plot (Figure 2) was linear to more than $70 \%$ extent of reaction which suggests a first order dependence of rate on [Col"EDTA2 ${ }^{2}$. Also the slope (0.98) of the logarithmic plot of $\mathrm{k}_{1}$ versus $\left[\mathrm{S}_{2} \mathrm{O}_{8}{ }^{2}\right]$ showed that the reaction is first order with respect to $\left[\mathrm{S}_{2} \mathrm{O}_{8}{ }^{2}\right]$. Hence, the reaction is second order overall. The second order rate constants, $k_{2}$ were fairly constant (Table 1.0) and equation (3) give the rate law for the reaction

$$
\begin{aligned}
& \frac{d\left[\operatorname{Co}(I I I) E D T A^{-}\right]}{d t}= \\
& k_{2}\left[\operatorname{Co}(I I) E D T A^{2-}\right]\left[S_{2} O_{8}^{2-}\right]
\end{aligned}
$$

Where

$$
k_{2}=(9.70 \pm 0.1) \times 10^{-2} \mathrm{dm}^{3} \mathrm{~mol}^{-1}
$$


Onu et al: Kinetics of Oxidation of Ethylenediammine-N,N,N',N'-tetraacetatocobaltate(II) complex....

Table 1: The pseudo-first order and second order rate constants for the reaction of [Co"lEDTA] ${ }^{2-}$ and $\mathrm{S}_{2} \mathrm{O}_{8}{ }^{2-}$ at [CollEDTA $\left.{ }^{2-}\right]=5.0 \times 10^{-3} \mathrm{~mol} \mathrm{dm}^{-3}, \mathrm{~T}=25 \pm 1^{\circ} \mathrm{C}$ and $\lambda_{\max }=520 \mathrm{~nm}$

\begin{tabular}{|c|c|c|c|c|c|}
\hline $\begin{array}{c}10^{3}\left[\mathrm{~S}_{2} \mathrm{O}_{8}{ }^{2-}\right] \\
\mathrm{mol} \mathrm{dm}{ }^{-3}\end{array}$ & $\begin{array}{c}10^{3}\left[\mathrm{H}^{+}\right] \\
\mathrm{mol} \mathrm{dm}-3\end{array}$ & $\begin{array}{l}1^{3}\left[\mathrm{Ag}^{+}\right] \\
\mathrm{mol} \mathrm{dm}{ }^{-3}\end{array}$ & $\begin{array}{l}10 \mathrm{NaNO}_{3} \\
\mathrm{~mol} \mathrm{dm}{ }^{-3}\end{array}$ & $\begin{array}{c}10^{3} \mathrm{k}_{\mathrm{obs}} \\
\mathrm{s}^{-1}\end{array}$ & $\begin{array}{c}10^{2} \mathrm{k}_{2} \\
\mathrm{dm}^{3} \mathrm{~mol}^{-1} \mathrm{~s}^{-1}\end{array}$ \\
\hline 30 & 10 & 10 & 50 & 2.9 & 9.7 \\
\hline 35 & 10 & 10 & 50 & 3.5 & 9.9 \\
\hline 40 & 10 & 10 & 50 & 3.9 & 9.8 \\
\hline 45 & 10 & 10 & 50 & 4.4 & 9.7 \\
\hline 50 & 10 & 10 & 50 & 4.8 & 9.7 \\
\hline 55 & 10 & 10 & 50 & 5.3 & 9.7 \\
\hline 60 & 10 & 10 & 50 & 5.8 & 9.6 \\
\hline 65 & 10 & 10 & 50 & 6.3 & 9.7 \\
\hline 70 & 10 & 10 & 50 & 6.7 & 9.5 \\
\hline 50 & 10 & 2.5 & 50 & 1.4 & 2.8 \\
\hline 50 & 10 & 5.0 & 50 & 2.8 & 5.5 \\
\hline 50 & 10 & 10 & 50 & 4.8 & 9.7 \\
\hline 50 & 10 & 20 & 50 & 7.1 & 14.3 \\
\hline 50 & 10 & 40 & 50 & 12.9 & 25.8 \\
\hline 50 & 2.5 & 10 & 50 & 4.5 & 9.1 \\
\hline 50 & 5.0 & 10 & 50 & 4.8 & 9.6 \\
\hline 50 & 10 & 10 & 50 & 4.8 & 9.6 \\
\hline 50 & 20 & 10 & 50 & 4.5 & 9.1 \\
\hline 50 & 40 & 10 & 50 & 4.5 & 9.1 \\
\hline 50 & 10 & 10 & 30 & 4.6 & 9.2 \\
\hline 50 & 10 & 10 & 40 & 4.8 & 9.7 \\
\hline 50 & 10 & 10 & 50 & 4.8 & 9.7 \\
\hline 50 & 10 & 10 & 60 & 4.8 & 9.7 \\
\hline 50 & 10 & 10 & 70 & 4.6 & 9.2 \\
\hline
\end{tabular}

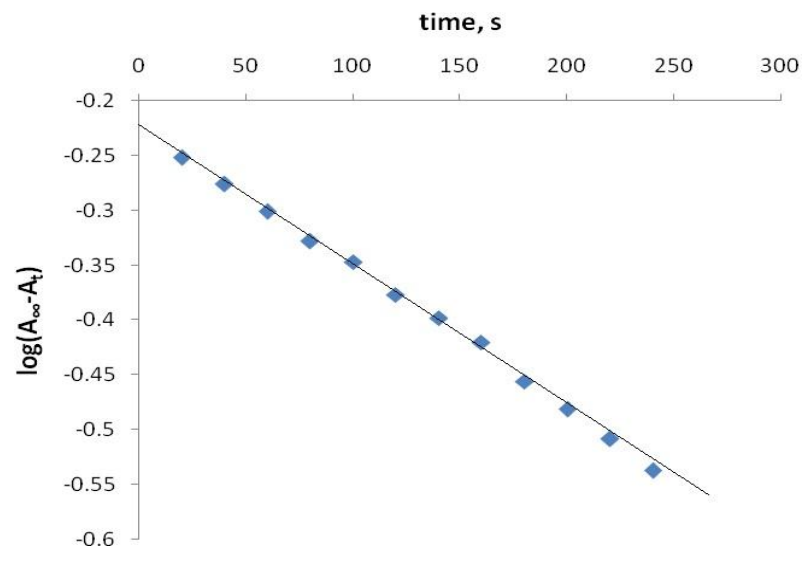

Figure 2: Typical pseudo-first order Plot for the reaction of [Co"EDTA] ${ }^{2-}$ with $\mathrm{S}_{2} \mathrm{O}_{8}{ }^{2-}$
The reaction rate neither showed dependence on the concentration of acid $\left(\left[\mathrm{H}^{+}\right]\right)$nor significant effect on change in ionic strength (Tables 1) of the reaction medium. However, the rate of the reactions increased in a first order manner with increase in catalyst, $\left(\mathrm{Ag}^{+}\right)$concentration within the range investigated. Also, plot of $k_{2}$ versus $\left[\mathrm{Ag}^{+}\right]$was linear with zero intercept (Figure 3). The catalyst dependent rate constant can be represented as:

$$
k_{2}=a\left[\mathrm{Ag}^{+}\right]
$$

Where $\mathrm{a}=5.90 \times 10^{-2} \mathrm{dm}^{3} \mathrm{~mol}^{-1} \mathrm{~s}^{-1}$ 


\section{Nigerian Journal of Basic and Applied Science (December, 2018), 26(2): 45-53}

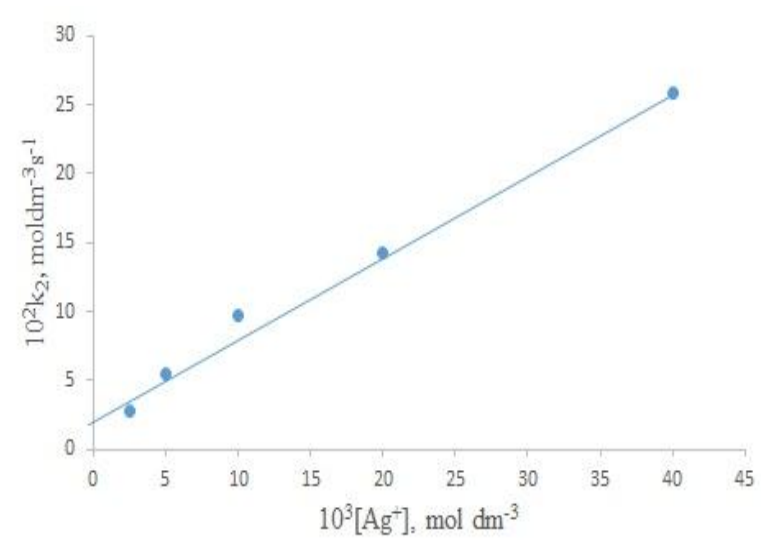

Figure 3: Plot of $\mathrm{k}_{2}$ versus $10^{3}\left[\mathrm{Ag}^{+}\right]$for the reaction of [CollEDTA] ${ }^{2-}$ with $\mathrm{S}_{2} \mathrm{O}_{8}{ }^{2-}$

The overall rate equation in the acid and catalyst concentration range investigated is:

$\frac{d\left[\mathrm{Co}(I I I) E D T A^{-}\right]}{d t}=$

$\left(a\left[\mathrm{Ag}^{+}\right]\right)\left[\mathrm{Co}(\mathrm{II}) \mathrm{EDT}^{2-}\right]\left[\mathrm{S}_{2} \mathrm{O}_{8}^{2-}\right]$ (5.0)

The rate of reaction was found to increase with addition of formate ion while negligible effect was observed upon addition of $\mathrm{K}^{+}$ion (Table 2 ).

Table 2: Effect of added ions on the reaction rate of [Co"EDTA] ${ }^{2-}$ with $\mathrm{S}_{2} \mathrm{O}_{8}{ }^{2-}$ at [Co"EDTA2-] $=5.0 \times$ $10^{-3} \mathrm{~mol} \mathrm{dm}^{-3},\left[\mathrm{~S}_{2} \mathrm{O}_{8}{ }^{2}\right]=5.0 \times 10^{-2} \mathrm{~mol} \mathrm{dm}^{-3}, \mathrm{I}=$ $0.5 \mathrm{~mol} \mathrm{dm}^{-3},\left[\mathrm{Ag}^{+}\right]=1.0 \times 10^{-2} \mathrm{~mol} \mathrm{dm}^{-3}, \mathrm{~T}=26$ $\pm 10 \mathrm{C}$ and $\lambda_{\max }=520 \mathrm{~nm}$

\begin{tabular}{|c|c|c|c|}
\hline $\bar{X}$ & $\begin{array}{l}10^{2}[\mathrm{X}] \\
\mathrm{mol} \mathrm{dm}^{-3}\end{array}$ & $\begin{array}{l}10^{3} \text { kobs, } \\
s^{-1}\end{array}$ & $\begin{array}{l}10^{2} \mathrm{k}_{2} \\
\mathrm{dm}^{3} \mathrm{~mol}^{-1} \mathrm{~s}^{-1}\end{array}$ \\
\hline \multirow[t]{6}{*}{$\mathrm{HCOO}$} & 0.0 & 4.84 & 9.67 \\
\hline & 1.0 & 5.07 & 10.13 \\
\hline & 2.0 & 5.99 & 11.98 \\
\hline & 3.0 & 6.45 & 12.90 \\
\hline & 4.0 & 6.68 & 13.36 \\
\hline & 5.0 & 7.14 & 14.28 \\
\hline \multirow[t]{6}{*}{$\mathrm{K}^{+}$} & 0.0 & 4.84 & 9.67 \\
\hline & 1.0 & 4.74 & 9.48 \\
\hline & 2.0 & 4.74 & 9.48 \\
\hline & 3.0 & 4.75 & 9.50 \\
\hline & 4.0 & 4.75 & 9.50 \\
\hline & 5.0 & 4.74 & 9.48 \\
\hline
\end{tabular}

From the temperature dependent study (Table 3) and Eyring plot (Fig.4), the enthalpy, $\Delta \mathrm{H}^{*}=+$ $39.27 \mathrm{~kJ} \mathrm{~mol}^{-1}$ and entropy, $\Delta \mathrm{S}^{*}=-136.73 \mathrm{JK}^{-1}$ $\mathrm{mol}^{-1}$ of activation were obtained.

Table 3: Activation parameters of the reaction of [CollEDTA] ${ }^{2-}$ with $\mathrm{S}_{2} \mathrm{O}_{8}{ }^{2-}$ at [CollEDTA ${ }^{2-}$ ] $5.0 \times 10^{-3} \mathrm{~mol} \mathrm{dm}^{-3},\left[\mathrm{~S}_{2} \mathrm{O}_{8}{ }^{2}\right]=5.0 \times 10^{-2} \mathrm{~mol} \mathrm{dm}^{-3}$, $\mathrm{I}=0.5 \mathrm{~mol} \mathrm{dm}{ }^{-3},\left[\mathrm{Ag}^{+}\right]=1.0 \times 10^{-2} \mathrm{~mol} \mathrm{dm}^{-3}$, $\mathrm{T}=26 \pm 10 \mathrm{C}$ and $\lambda_{\max }=520 \mathrm{~nm}$

\begin{tabular}{|c|c|c|}
\hline $\begin{array}{l}\text { Temperature, } \\
\mathrm{K}\end{array}$ & $\begin{array}{l}10^{3} k_{\text {obs }} \\
s^{-1}\end{array}$ & $10^{2} \mathrm{k}_{2}, \mathrm{dm}^{3} \mathrm{~mol}^{-1} \mathrm{~s}^{-1}$ \\
\hline 309 & 5.3 & 10.59 \\
\hline 319 & 8.98 & 17.96 \\
\hline \multirow[t]{2}{*}{329} & 14.28 & 28.56 \\
\hline & $\begin{array}{l}\Delta \mathrm{H}^{*}= \\
+39.27 \\
\mathrm{kJmol}-1\end{array}$ & $\begin{array}{l}\Delta \mathrm{S}^{*}=-136.73 \mathrm{JK}- \\
{ }^{1} \mathrm{~mol}^{-1}\end{array}$ \\
\hline
\end{tabular}

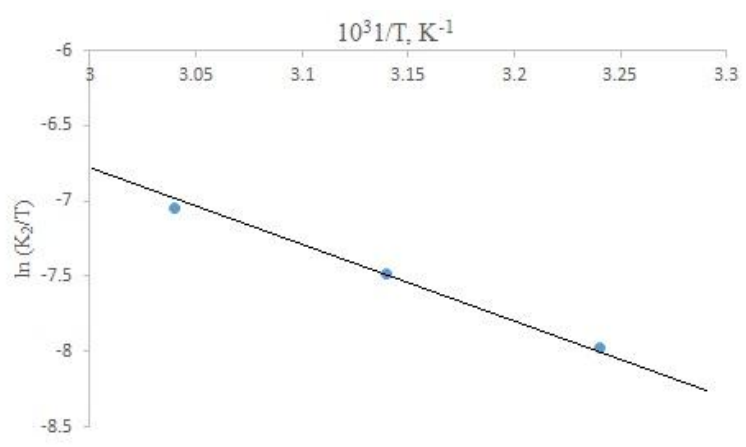

Figure 4: Plot of $\ln \left(\frac{k 2}{T}\right)$ versus $\frac{1}{T}$ for the reaction of [CollEDTA] ${ }^{2-}$ with $\mathrm{S}_{2} \mathrm{O}_{8}{ }^{2-}$

Free radical specie was detected in the reaction by the formation of gelatinous precipitate upon addition of $5.0 \mathrm{~cm}^{3}$ acrylamide followed by excess methanol.

The Michaelis-Menten type plot of $1 / \mathrm{k}_{\text {obs }}$ versus $1 /$ [oxidant] was linear with zero intercept (figure 5). 


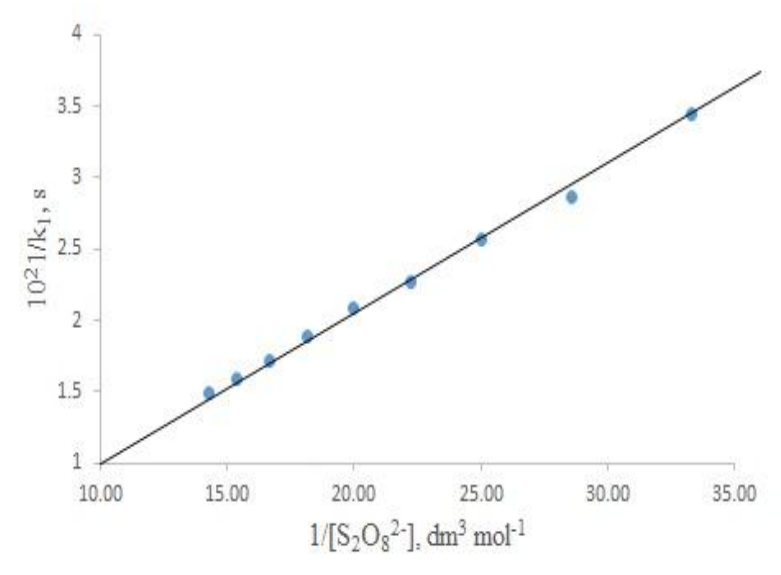

Figure 5: Michaelis-Menten type plot for the reaction of [Co"EDTA] $]^{2-}$ with $\mathrm{S}_{2} \mathrm{O}_{8}{ }^{2-}$

\section{DISCUSSION}

The stoichiometry of 2:1 obtained in this study is in agreement with the result of oxidation of $\mathrm{Co}(\mathrm{II})$ complexes (Banerjee and Pujari, 1981, Onu et.al., 2009, 2015) and for the reaction of transition metal complex with persulphate ion (Gupta, 1986). Based on the stoichiometry, a two electron reduction of the persulphate ion to yield $\mathrm{SO}_{4}^{2-}$ ion product is envisaged. The envisaged $\mathrm{SO}_{4}{ }^{2-}$ product was confirmed qualitatively by the formation of white precipitate insoluble in excess dilute $\mathrm{HCl}$ when $\mathrm{BaCl}_{2}$ was added to the solution of the reaction product. $\mathrm{Co}$ (III) as a product was confirmed electronically by its characteristic two $\lambda_{\max }$ at $382 \mathrm{~nm}$ and $536 \mathrm{~nm}$ (Mansour, 2003; Perveen et al., 2013 and Onu et.al., 2009, 2015 and 2016) when the spectrum of the solution of the product of the reaction was scanned.

The results of the kinetic study showed first order dependence with respect to both [Co(II)EDTA2 $]$ and $\left[\mathrm{S}_{2} \mathrm{O}_{8}{ }^{2}\right]$. Similar first order dependence on $\left[\mathrm{S}_{2} \mathrm{O}_{8}{ }^{2}\right]$ was reported on its redox reaction with malachite green (Mohammed et al., 2010).

Variation of hydrogen ion concentration showed no effect on the reaction rate implying that protonation or deprotonation of any of the reactant species was unimportant during the course of the reaction. Gupta and Ghosh (1959), Banerjee and Pujari (1983) and Rao et.el., (1987) obtained similar result for the redox reaction of $\mathrm{S}_{2} \mathrm{O}_{8}{ }^{2-}$. However the reaction is first order with respect to catalyst concentration. The dependence of reaction on the concentration of catalyst is common for the redox reaction involving persulphate ion (Gupta 1986) since transition metal catalyst such as $\mathrm{Ag}(\mathrm{I})$ (Ayoko et. al.,1992; Gong and Lin, 2011) and Fe(II) (Tang et.al, 2015) activate the persulphate ion so as to facilitate its reduction. Despite the very high redox potential $(E=+2.12 \mathrm{~V})$ of persulphate ion (Burgess, 1999), its electron transfer reaction is slow due to the strong -0-O- bond present which should be broken enroute the formation of the $\mathrm{SO}_{4}{ }^{2-}$ product. Hence the role of the catalyst in this titled reaction becomes very germane.

The rate of the reaction surprisingly showed no significant effect with change in ionic strength of the reaction medium in the concentration range investigated (Tables 1) suggesting a zero Bronsted-Debye salt effect (Benson, 1969). Such salt effect can be occasioned when the activated complex is composed of either one or both neutral reactant partners (Atkins and de Paula, 2002) or due to ion pair effect. Given that the redox partners are divalent anions coupled with acid independent nature of the reaction, obtaining neutral species to give zero BronstedDebye effect seems remote. The zero BronstedDebye effect may have been occasioned by ionpair effect. This tendency is further supported by the negative value of activation entropy $\left(\Delta S^{*}=\right.$ $155.88 \mathrm{~J} \mathrm{~K}^{-1} \mathrm{~mol}^{-1}$ ) which is indicative of a more ordered activated complex. Free radical test was positive which indicated the presence of free radical specie in one of the reaction steps.

Michaelis - Menten plot of $1 / \mathrm{k}_{\text {obs }}$ versus $1 /\left[\mathrm{S}_{2} \mathrm{O}_{8}{ }^{2}\right]$ had zero intercept which suggests the absence of an intermediate complex in the rate determining step. Rationalizing the above results therefore, the reaction is possibly occurring through the outer-sphere mechanism via an ion pair: The mechanistic scheme below explain the experimental data. 


$$
\begin{aligned}
& \mathrm{Ag}^{+}+\mathrm{S}_{2} \mathrm{O}_{8}^{2-} \rightleftharpoons \mathrm{Ag}^{+}, \mathrm{S}_{2} \mathrm{O}_{8}^{2-}, \mathrm{K}_{1} \\
& {[\mathrm{Co}(I I) E D T A]^{2-}+\mathrm{Ag}^{+}, \mathrm{S}_{2} \mathrm{O}_{8}^{2-} \rightarrow[\mathrm{Co}(\mathrm{III}) E D T A]^{-}+\mathrm{SO}_{4}^{2-}+\mathrm{Ag}^{+}+\mathrm{SO}_{4}^{-}, k_{2}, \text { slow }} \\
& {[\mathrm{Co}(\mathrm{II}) E D T A]^{2-}+\mathrm{SO}_{4}^{-} \cdot \rightarrow[\mathrm{Co}(\mathrm{III}) E D T A]^{-}+\mathrm{SO}_{4}^{2-}, \mathrm{k}_{3}} \\
& \frac{d[\mathrm{Co}(I I I) E D T A]^{-}}{d t}=k_{2}\left[\mathrm{Co}(I I) E D T A^{2-}\right]\left[\mathrm{Ag}^{+}, \mathrm{S}_{2} \mathrm{O}_{8}^{2-}\right] \\
& \text { But }\left[\mathrm{Ag}^{+}, \mathrm{S}_{2} \mathrm{O}_{8}^{2-}\right]=K_{1}\left[\mathrm{~S}_{2} \mathrm{O}_{8}^{2-}\right]\left[\mathrm{Ag}^{+}\right] \\
& \frac{d\left[\mathrm{Co}(\mathrm{III}) E D T A^{-}\right]}{d t}=\left(\mathrm{K}_{1} \mathrm{k}_{2}\left[\mathrm{Ag}^{+}\right]\right)\left[\mathrm{Co}(\mathrm{II}) E D T A^{2-}\right]\left[\mathrm{S}_{2} \mathrm{O}_{8}^{2-}\right]
\end{aligned}
$$

Which is in analogues to Eq. 4.0, where $a=K_{1} k_{2}$

\section{CONCLUSION}

The kinetics of oxidation of ([Co(II)EDTA $]^{2-}$ ) by silver-activated persulphate ion in aqueous nitric acid medium have been studied. Stoichiometric study showed that two moles of the reductant were consumed by one mole of the Oxidant. The rate of reaction was independent on the concentration of acid, but varied linearly with catalyst concentration. The reaction displayed zero salt effect which was rationalized in terms of ion-pair effect. The Michaelis-Menten's plot gave zero intercept indicating the absence of intermediate complex. Also the activation parameters calculated are: $\Delta \mathrm{H}^{*}=+39.27 \mathrm{~kJ}$ mol${ }^{1} \Delta \mathrm{S}^{*}=-1336.73 \mathrm{JK}^{-1} \mathrm{~mol}^{-1}$. Based on the experimental evidences the reaction is proposed to occur by the outer-sphere mechanism via an ion pair route.

\section{REFERENCES}

Anderegg , G., Arnaud-New, F., Delgado, R., Felcman, J. and Popov, K.(2005). Critical Evaluation Of Stability Constants Of Metal Complexes Of Complecones For Biomedical And Environmental Applications, Pure and Applied Chemistry, 77(8), 1445-1495. Doi:10.1351/pac200577081445

Atkins, P.W. and de Paula, J. (2002). Physical Chemistry. $7^{\text {th }}$ ed., Oxford University Press, p.962.
Ayoko, G.A, lyun, J.F and El - Idris, I.F (1991). Electron Transfer At Tetrahedral Cobalt(II) Part I. Kinetic Of Bromate Ion Reduction, Transition Metal Chemistry, 16, $145-148$.

Banarjee, P. and Pujari, P.M. (1983). Kinetics Of The $\mathrm{S}_{2} \mathrm{O}_{8}{ }^{2-}$ And $\mathrm{H}_{2} \mathrm{O}_{2}$ Oxidation $\mathrm{Of}$ Trans-1,2-Diaminocychohexane$\mathrm{N}, \mathrm{N}, \mathrm{NI}, \mathrm{Nl},-$ Tetraacetatecobaltate(II) In Acidic And Basic Buffer Media, Transition Metal Chemistry, 8:.91-98.

Banerjee, P and Pujari, P.M (1981). The Kinetics Of Oxidation of $\mathrm{N}(2-$ Hydroxyl)Ethylenediamminetetraacetatec obaltate(II) By $\mathrm{S}_{2} \mathrm{O}_{8}{ }^{2-}$ In Aqueous Acidic Solution, Transition Metal Chemistry, 6, 47-54.

Benson, D. (1969). Mechanism Of Inorganic Reactions In Solution. McGraw- Hill U.K., pp. 153.

Burgess J. (1999). Ions in Solution: Basic Principles of Chemical Interaction, $2^{\text {nd }}$ ed. WoodHead Publishing, USA, p. 168.

Chang, R. (2000). Physical Chemistry for the Chemical and Biological Sciences, $3^{\text {rd }}$ ed., University Science Books.

Dharmaraja, J.; Balamurugan, J.; and Shobana S. (2013). Synthesis, Structural Elucidation, Microbial, Antioxidant And Nuclease Activities Of Some Novel Divalent M(II) Complexes Derived From 
Onu et al: Kinetics of Oxidation of Ethylenediammine-N,N,N',N'-tetraacetatocobaltate(II) complex....

5-Fluorouracil And L-Tyrosine, Journal of Saudi Chemical Society , 21(1), 567-576.

Gong, Y. and Lin, L. (2011). Oxidative

Decarboxylation Of Levulinic Acid By

Silver/Persulphate , Molecules, 16, 27142725.

Gupta, K.Y. (1986). Catalysis in Inorganic Redox Reaction and Mechanism. Proceedings of Indian National of Science Academy, 52: $837-847$.

Gupta, K.Y. and Ghosh, S. (1959). Hydrogen lon Dependence Of The Oxidation Of Iron(II) With Peroxydisulphate In Acidic Perchlorate Solutions. Inorganic Chemistry, 20: 434 439.

Harald, J., Stefan, L., Thomas, L., Sylvia, J. and Sven, G. (2005). "Peroxo Compounds, Inorganic", Ullmann's Encyclopedia of Industrial Chemistry, Weinheim:Wiley$\mathrm{VCH}$, doi:10.1002/14356007.a19_177.pub2.

Mansour, A.M. (2003) Kinetics and Mechanism of the Oxidation of $[\mathrm{N}-(2-$ Hydroxyethyl)Ethylenediamine-N',N',N'Triacetatocobalt(II) by Vanadate Ion, Transition Metal Chemistry, 28, 276-279.

Mcheik, A.H. and El Jamal, M.M. (2013). Kinetic Study of the Discoloration of Rhodamine $B$ with Persulphate, Iron Activation, Journal of Chemical Technology and Metalurgy, 48(4):357- 365.

Mohammed, Y., Iyun, J.F. and Idris, S.O. (2010). Silver - Catalyzed Peroxydisulphate Oxidation of Malachite Green in Aqueous Acidic Medium: Kinetic And Mechanistic Approach, International Journal of Chemistry, 20(2): 105 - 112.

Naik, R. M., Srivastava, A., Tiwara, A. K., Yadav, S.B. S. and Verma, A. K. (2007). Kinetic And Mechanism Studies Of Amine-NPolycarboxylates Complexes Of Cobalt(II) By Periodate Ions In Aqueous Medium, Journal of Iranian Chemical Society, 4(1): $63-71$.

Naik, R.M.; Kumar, B.; Rai, J.; Rastogi, R. and Yadav S.B.S. (2010). Kinetics And
Mechanism Of Oxidation Of Hexamethylenediaminetetraacetatocobal tate(II) Complex By Periodate Ion In Aqueous Medium, E-Journal of Chemistry, 7(51), 5391 - 5399 .

Kun-Chang, H., Richard, A.C. and George, E.H. (2002). Kinetics of Heat-Assisted Persulphate Oxidation Of Methyl TertButyl Ether, Chemosphere, 49: 413-420.

Onu, A.D., lyun, J.F. and Idris, S.O. (2008). Reduction Reaction of [Cohedtaoh ${ }_{2}{ }^{-}$ With $\mathrm{NO}_{2}-$ In Aqueous Perchloric Acid Medium: Kinetics and Mechanisms, CHEMCLASS Journal, 5,55-61.

Onu, A.D., Iyun, J.F. and Idris, S.O. (2009). The Kinetics of the Reduction of Tetraoxoiodate(VII) by n-(2Hydroxyethyl)Ethylenediaminetriacetatoc obaltate(II) Ion in Aqueous Perchloric Acid. Transition Metal Chemistry, 34, 849-853.

Onu, A.D., Iyun, J.F. and Idris, O.S. (2015) Kinetics and Stoichiometry of the Reduction of Hydrogen peroxide by an Aminocarboxylactocobaltate(II) Complex in Aqueous Medium. Open Journal of Inorganic Chemistry, 5, 75-82.

Onu, A.D., lyun, J.F. and Idris, S.O. (2016).Oxidation Of Ethylenediaminetetraacetatocobaltate(II) Complex By Hydrogen Peroxide In Aqueous Acidic Medium: A Kinetics study, Journal of Chemical Society of Nigeria, 41(2), $81-86$.

Perveen, A.; Nezemoleslam, T. and Naqvi, I.I. (2013). Preparation Of Cobalt(III) Complexes With Trans-1,2Diaminocyclohexane-N,N,N',N'-

Tetraacetic Acid And Ethylenediamminetetraacetic Acid, African Journal of Pure and Applied Chemistry.7(6).218-224.

Rao, K.V., Rao, J.K., Sivaswaroop, P, and Kumar, A.K (1987). Kinetic Of Stepwise Oxidation Of Manganese(II) $\mathrm{By}_{2} \mathrm{O}_{8}{ }^{2-}$ In Phosphoric Acid Medium, Transition Metal Chemistry, 12: 442-448. 
Shen-Xin, L., DongWei, N.M., ZongWei, C., Xiang-Rong, X., Hua-Bin, L. and Yue, J. (2009). Degradation Of Diphenylamine By Persulphate: Performance Optimization, Kinetics and Mechanism, Journal of Hazard Mater, 164: 26-31.

Swaroop, S.P., Kumar, A.K and Rao, V.K.P.(1991). Oxidation of Cobalt(II)aminopolycarboxylate complexes by peroxomonophosphoric acid in acetate buffers: a Kinetic study. Transition Metal Chemistry, 16(4), 416 418.

Tang, X. Hashmi, M.Z.; Zeng, B.; Yang, J. and Shen, C. (2015). Application Of IronActivated Persulfate Oxidation For The Degradation of PCBs in Soil, Chemical Engineering Journal (279), 673 - 680.

Vogel, A.I. (1979). Vogel's Textbook of Macro and Semimicro Qualitative Inorganic
Analysi, $5^{\text {th }}$ Ed. Longman, New York. pp. 325- 346.

Vuckovic, G.; Antonijevic-Nikolic, M.; Tanaskovic, S.B.; and Zivkovic-Rodovanovic, V. (2011). New $\mathrm{Cu}(\mathrm{Il})$ and Co(II)octaazamacrocyclic complexes with 2-amino-3-phenylpropanoic acid, Journal of the Serbian Chemical Society, 76(5), 719 - 731.

Xiang-Rong, X. and Xiang-Zhong, L. (2010). Degradation of Azo Dye Orange $G$ in Aqueous Solutions by Persulfate with Ferrous Ion, Separation and Purification Technololgy, 72: 105-111.

Xie, X., Zhang, Y., Huang, W. and Huang, S. (2012). Degradation kinetics and mechanism of aniline by heat-assisted persulfate oxidation, Journal of Environmental Sciences, 24(5): 821-826. 